\title{
The use of Bovhyaluronidaze azoximer preparation in the treatment of suppurative wounds in companion animals
}

\author{
Anna Nazarova*, Boris Semenov, Anatoly Stekolnikov, and Tatiana Kuznetsova \\ Saint-Petersburg State University of Veterinary Medicine, 196084 Saint Petersburg, Russia
}

\begin{abstract}
Increasing the number of dogs and cats kept in urban households makes relevant research of new effective methods of treatment of companion animals. We conducted studies of the effect of Bovhyaluronidaze azoximer on the treatment duration of suppurative wounds. The study was carried out on 42 animals (24 cats and 18 dogs) with septic processes in two groups. The animals of the both groups were given conventional therapy; in animals of the experimental group the Bovhyaluronidaze azoximer preparation was additionally included as a part of a complex therapy. The effect of the use Bovhyaluronidaze azoximer preparation was evaluated by three indicators: the wound cleansing from purulonecrotic masses duration, the duration of existence of edema, the number of managements of wound. The median wound cleansing time in the experimental group improve on 2.29 days. The median duration of existence of edema in the experimental group was in less time on 1.57 days in comparison with the control group. The median number of required managements of wound is reduced by 5.00 manipulations in the experimental group in comparison with the control group. The results of our study show that Bovhyaluronidaze azoximer can be recommended for use in the therapy of suppurative wounds.
\end{abstract}

\section{Introduction}

Over the past decades, the number of companion animals kept in urban households has been increasing rapidly. According to Interfax in 2018, there were about 33.7 million cats and 18.9 million dogs in the country [1]. The fact that dog and cat owners regularly go to veterinary clinics, and $68 \%$ of owners do this more than once a year, is taking veterinary medicine of small pets to a new level of demand. In this regard, research and development of new effective methods of treatment and prevention of diseases of companion animals, and the study and expansion of the use of both veterinary and medical preparations in veterinary practice are necessary.

There is recent research in advanced treatment methods of inflammatory and purulent processes. The use of silver [2, 3], probiotics [4], curcumin oil [5] preparations and new wound dressing [6] in the treatment of suppurative wounds is being investigated. However, this is a topical wound therapy. At the same time, the use of systemic medications in the treatment of suppurative wounds has not been sufficiently studied.

One of these preparations, which is currently being studied at the Department of Obstetrics and Operative Surgery of the St. Petersburg State University of Veterinary Medicine, is the Bovhyaluronidaze azoximer preparation (lat.: Bovhyaluronidazum azoximerum), which is a stabilized form of the enzyme hyaluronidase (hyaluronidase conjugate with a high- molecular derivative of poly-1,4-ethylene piperazine N-oxide). Development and production of NPO "Petrovax Pharm", Russia.

During the course of the research on the prevention of postoperative complications in urological patients, we found that the Bovhyaluronidaze azoximer has an antiinflammatory effect, reduces the severity of edema of tissue of the surgical wound and tissue around urethrostomy, thereby reducing the frequency and severity of complications after surgical interventions on the urethra and the bladder [7, 8].

Since edema and inflammation of the tissues are present in various purulent processes, including bitten wounds, phlegmons and abscesses (including inflammation and abscesses of the perianal sinuses), we conducted studies the effect of the Bovhyaluronidaze azoximer over the course of these processes and the treatment duration.

\section{Materials and methods}

The study was conducted at the facilities of Bars veterinary clinic chain in the city of St. Petersburg, Russia and St. Petersburg State University of Veterinary Medicine.

The study of the effect of Bovhyaluronidaze azoximer on the course and treatment duration of suppurative wounds and abscesses was carried out on $\mathbf{4 2}$ animals admitted to veterinary clinics with complaints about development of septic processes. 
24 animals were Felis domestica (Felis catus), 18 animals were Canis lupus familiaris. The animals were randomly divided into two groups. The experimental group included 12 cats (10 males and 2 females) and 9 dogs (4 males and 5 females). The control group included 12 cats $(9$ males and 3 females) and 9 dogs ( 5 males and 4 females).

The median age of the dogs in the experimental group was $5.67 \pm 1.32$ years old, in the control $5.89 \pm 1.36$ years old. The median weight of the dogs was $\quad 6.02 \pm 4.51 \mathrm{~kg} \quad$ and $\quad 6.07 \pm 4.21 \mathrm{~kg}$ in the experimental and control groups respectively (standard deviation is indicated).

The median age of the cats in the experimental group was $6.14 \pm 3.43$ years old, in the control $6.48 \pm 3.54$ years old. The median weight of the cats was $5.14 \pm 1.22 \mathrm{~kg}$ and $5.25 \pm 1.28 \mathrm{~kg}$ in the experimental and control groups respectively (standard deviation is indicated).

In 11 dogs (six dogs in the experimental group and five dogs in the control group) and 13 cats (seven cats in the experimental group and six cats in the control group) a perianal sinuses abscesses were diagnosed. Owners of 7 dogs (three dogs of the experimental group and four dogs of the control group) and $\mathbf{9}$ cats (four cats of the experimental group and five cats of the control group) appealed about the development of a purulent process against from bitten wounds. One cat from each group was diagnosed with a complication after castration caused by self-mutilation.

Clinical examination of all animals was carried out in accordance with GOST R 58090-2018 "Clinical examination of unproductive animals" [9].

The animals of the both groups were given conventional therapy, which included primary surgical treatment of the wounds, the daily debridement using Chlorhexidine bigluconate solution aqueous $0.05 \%$, Oflomelid ${ }^{\circ}$ ointment (pharmacologically active substances: Ofloxacine, Metyluracil, Lidocaine hydrochloride). Systemic antimicrobials: for animals with bitten wounds Lincomycin hydrochloride solution $30 \%$ was administered intramuscularly $10 \mathrm{mg} / \mathrm{kg} \mathrm{q} 12 \mathrm{~h}$ 20 administrations; for animals with inflammation and perianal sinuses abscesses Amoxicillin $15 \%$ suspension for injection was administered intramuscularly $15 \mathrm{mg} / \mathrm{kg}$ q24h 10 administrations.

In animals of the experimental group, the Bovhyaluronidaze azoximer in the form of rectal suppositories was additionally included as a part of a complex therapy.

The following indicators were recorded:

1. Wound cleansing from purulonecrotic masses duration (in days).

2. Duration of existence of edema (in days).

3. The number of managements of wound (at the rate of one wound debridement per day).

We performed the statistical analysis in Microsoft Excel 2016 and BioStat, AnalystSoft Inc., version 7.

The statistical significance (alpha level) adopted in this study is $5 \%(\mathrm{p}=0.05)$. To compare the results obtained in the experimental and control groups, we used the Mann-Whitney $\mathrm{U}$ Test. If the significance level $p$ obtained by applying the criterion was less than 0.05 , the differences between the groups were recognized as statistically significant.

\section{Results}

All animals of the experimental group well tolerated the use of the Bovhyaluronidaze azoximer in the form of rectal suppositories. No side effects of this preparation were observed during the study.

Bovhyaluronidaze azoximer preparation was administered rectally $750 \mathrm{IU}$ per animal q48h 5 administrations.

\subsection{The wound cleansing from purulonecrotic masses duration}

The wound cleansing from purulonecrotic masses duration in the experimental group was $1.86 \pm 0.65$ days (the standard deviation is indicated hereinafter). In the control group, this time was $4.14 \pm 1.01$ days.

In figure 1 shows the state of the wound on the third day after incision and drainage of a perianal sinus abscess in a cat from the control group: a purulent scab was removed during management of wound, profuse purulent discharge, pronounced edema and a induration of the perianal tissues were noted.

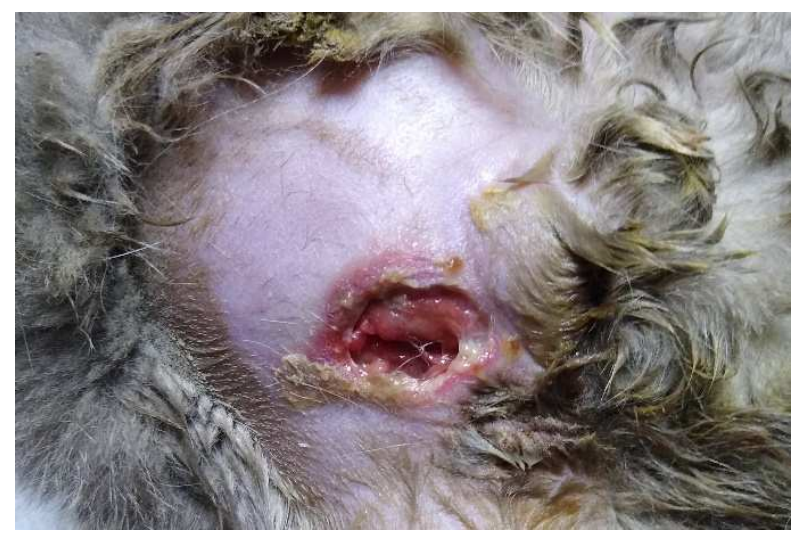

Fig. 1. The state of the wound on the third day after incision of a perianal sinus abscess (animal from the control group)

Confidence intervals for the wound cleansing from purulonecrotic masses duration: in experimental group 1.56-2.16 days and in the control group 3.68-4.60 days (see figure 2).

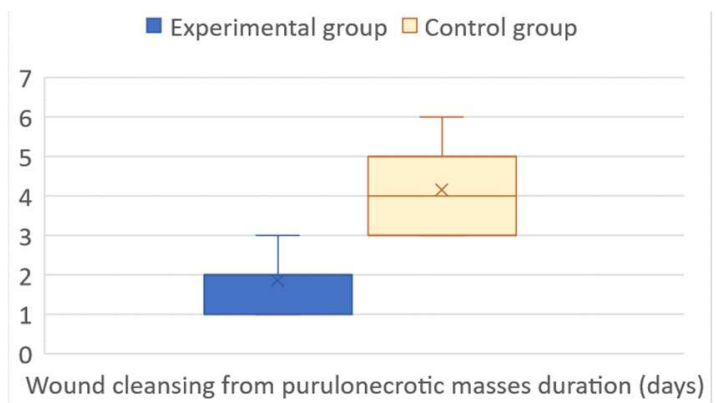

Fig. 2. Confidence intervals for the wound cleansing from purulonecrotic masses duration in the experimental and control groups 


\subsection{The duration of existence of edema}

The duration of existence of edema in the experimental group was $3.43 \pm 0.51$ days.

Figure 3 shows an edema over the right perianal sinus in a 10-year-old cat of the Don Sphynx breed, admitted to the clinic in connection with a relapse of the perianal sinus abscess.

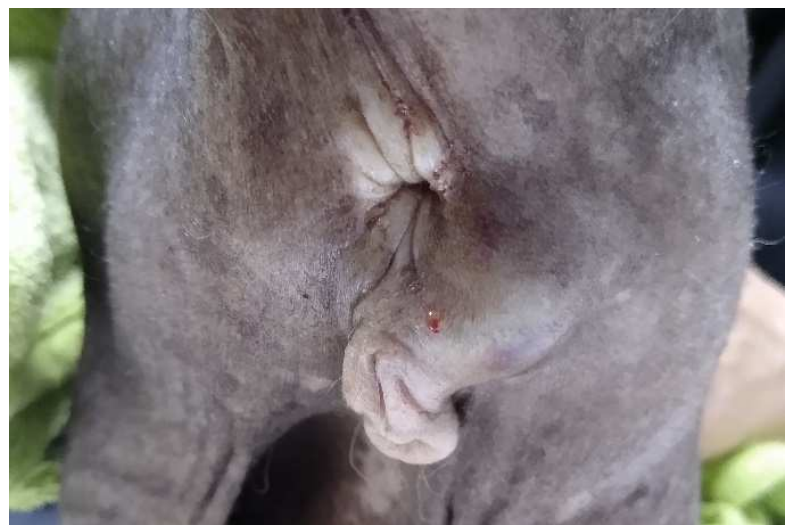

Fig. 3. Edema over the right perianal sinus before surgical opening of the abscess (animal from the experimental group)

It was decided not to use a systemic antibacterial on this animal. On the fourth day of treatment with the Bovhyaluronidaze azoximer preparation, the edema completely subsided, the abscess cavity was completely cleansed and significantly decreased (see figure 4).

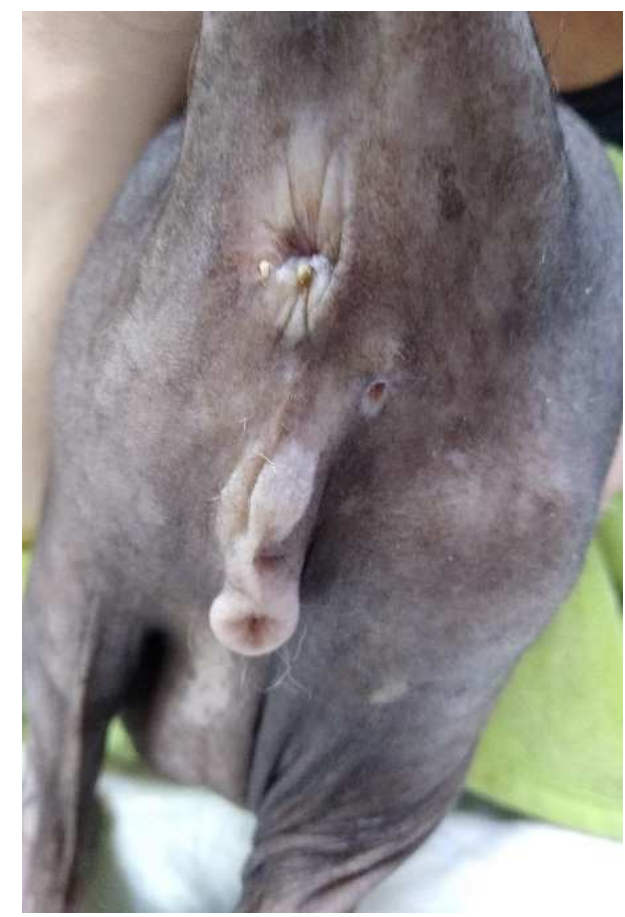

Fig. 4. The same animal as in figure 3, on the fourth day of treatment

The duration of existence of edema in the control group was $5.00 \pm 0.77$ days.

Confidence intervals for the duration of existence of edema in experimental group was 3.20-3.66 days and in the control group 4.65-5.35 days (see figure 5).

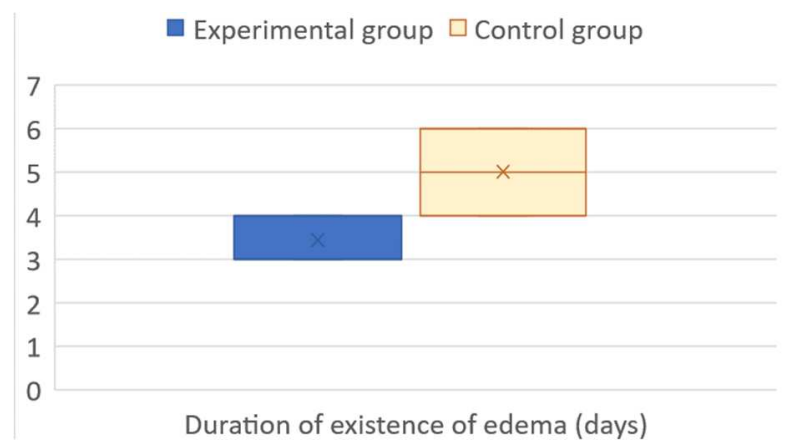

Fig. 5. Confidence intervals of the duration of existence of edema in the experimental and control groups

\subsection{The number of managements of wound}

The animals of the experimental group had need $8.43 \pm 1.21$ managements of wound (one wound debridement per day).

In figure 6 presents the state of the wound of a 6-year-old cat who was admitted to the clinic ten days after another cat bit her. The day before the reception of the owners noticed a strong swelling and tenderness near the tail, there was lethargy and anorexia. In the clinic, we performed incision an abscess, which was formed at the site of a bite wound at the tail base area. During the revision of the wound, an extensive cavity of $60 \times 50 \mathrm{~mm}$ in size with a purulent-hemorrhagic discharge was found. Surgical treatment of the wound was performed, and passive drains were installed.

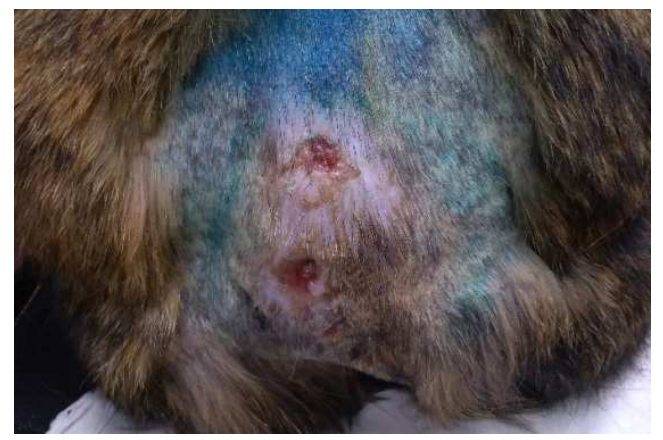

Fig. 6. The state of the bitten wound after initial surgical debridement (animal from the experimental group)

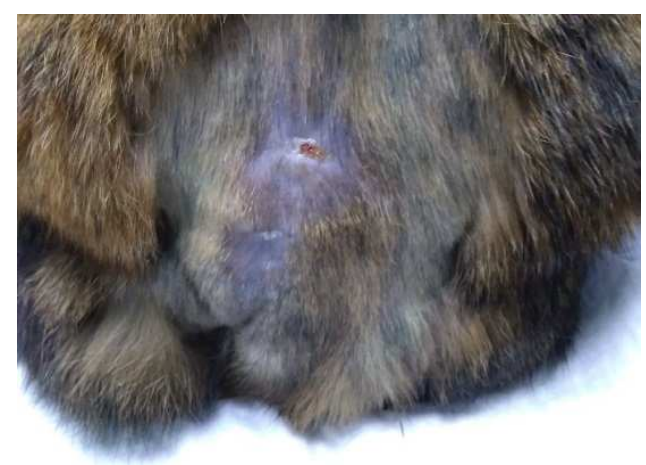

Fig. 7. The same animal as in figure 6 , after the ninth management of wound

On the ninth day of treatment with the Bovhyaluronidaze azoximer preparation, the cavity is 
absent, the wound openings are completely healed (see figure 7).

Figure 8 shows the state of the wound in a 7-year-old cat who was admitted to the clinic for the right perianal sinus abscess. Seven days earlier, the owners turned to another clinic, where a lancing of abscess was performed. Physical examination revealed grave condition of the cat, hyperthermia (body temperature $39.6^{\circ} \mathrm{C}$ ), a bulge was palpated dorsally to the closure of the surgical wound (from opening the previous abscess), and a purulent discharge was found during the puncture. After incision the abscess, a cavity with abundant purulent-fibrin contents and fibrin strands were found.

The animals of the control group needed $13.43 \pm 2.11$ managements of wound (one wound debridement per day).

Confidence intervals for the number of managements of wound in experimental group was 7.88-8.96 manipulations and in the control group 12.4-14.39 manipulations (see figure 10).

A summary chart for all the indicators taken into account is presented in figure 11 .

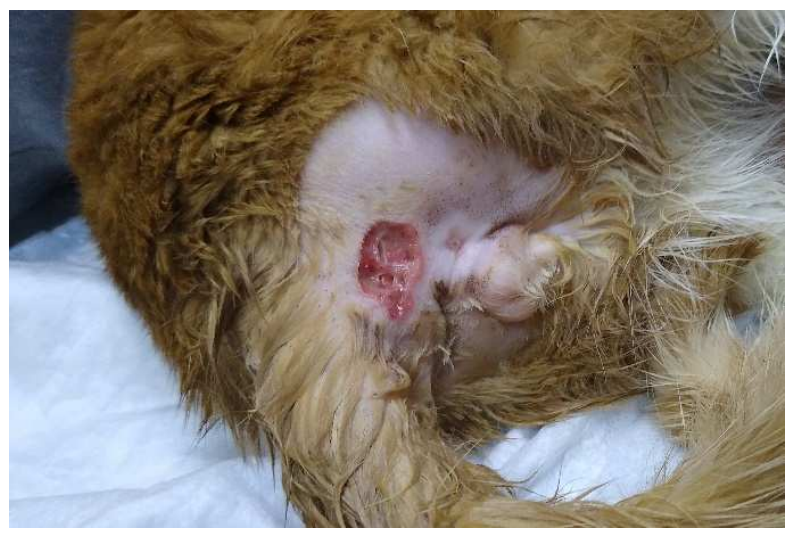

Fig. 8. Recurrent perianal sinus abscess

On the tenth day of treatment, the condition of the cat was satisfactory, the abscess cavity was absent, and there were no signs of inflammation (see figure 9).

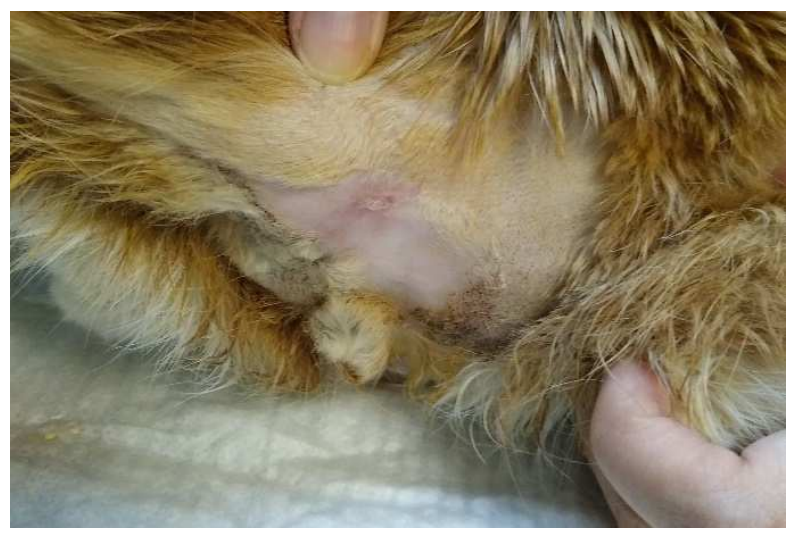

Fig. 9. The same animal as in figure 8 after the ninth management of wound (animal from the experimental group)

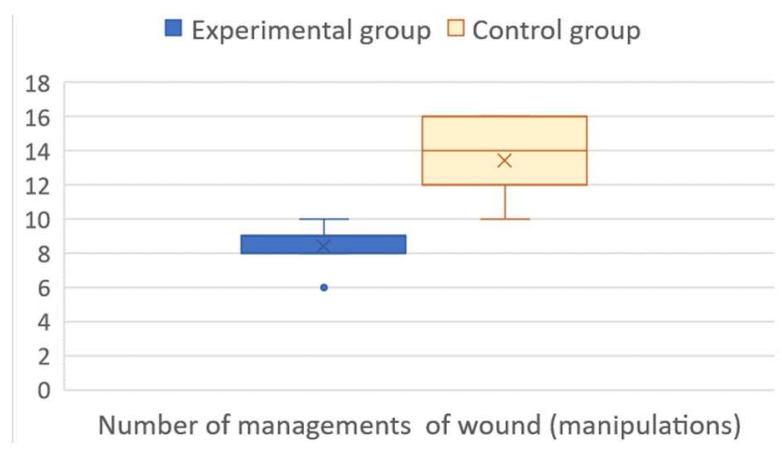

Fig. 10. Confidence intervals for the number of managements of wound in the experimental and control groups

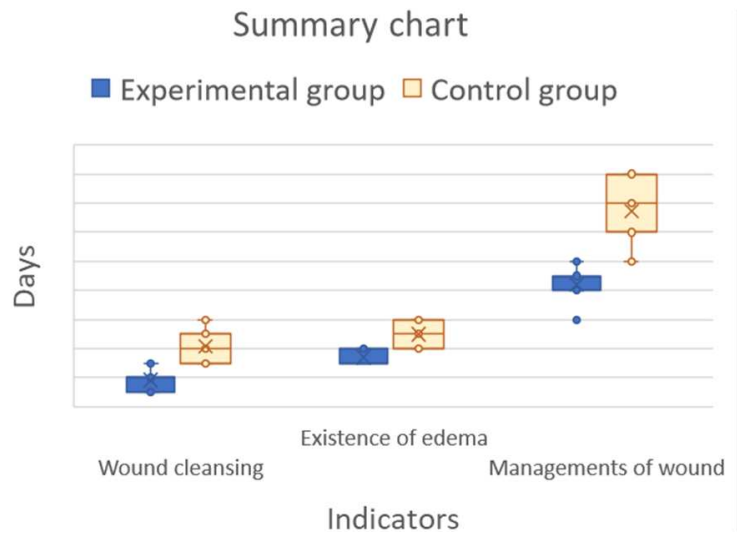

Fig. 11. Confidence intervals for three indicators in the experimental and control groups

\section{Discussion}

Bovhyaluronidaze azoximer (lat.: Bovhyaluronidazum azoximerum) is an immobilized hyaluronidase a conjugate of hyaluronidase with a high-molecular carrier. Due to hydrolysis of hyaluronan (high-molecular hyaluronic acid) to tetrasaccharides [10], hyaluronidase reduces the viscosity of the extracellular matrix of connective tissue, which increases the permeability of tissues, facilitates the movement of fluids in the interstitial spaces, and prevents the formation of a focus of chronic infection.

The high-molecular carrier, being an activated derivative of poly-1,4-ethylene piperazine $\mathrm{N}$-oxide, also has its own pharmacological activity and regulates the synthesis of inflammatory mediators interleukin-1 (IL-1) and tumor necrosis factor-alpha (TNF- $\alpha)$ [11].

Due to the combined actions of the components, Bovhyaluronidaze azoximer reduces edema and tissue inflammation, promotes to restore microcirculation, provides increased bioavailability of antibacterial in the pocket of infection.

The results of our study indicate that when using the Bovhyaluronidaze azoximer in the form of rectal suppositories as part of the complex therapy of purulentinflammatory processes, it accelerates the recovery of patients.

Thus, the median wound cleansing from purulonecrotic masses duration is reduced by 2.29 days. When comparing the results obtained in the experimental and control groups using the Mann-Whitney U Test, the 
p-value is $0.10 \times 10^{-6}$, which indicates that the difference is statistically significant.

The median duration of existence of edema is reduced by 1.57 days. When comparing the results obtained in the experimental and control groups using the Mann-Whitney U Test, the p-value is $1.13 \times 10^{-6}$, which indicates that the difference is statistically significant.

The median number of managements of wound is reduced by 5.00 manipulations. When comparing the results obtained in the experimental and control groups using the Mann-Whitney $U$ Test, the p-value is $0.06 \times 10^{-6}$, which is also much less than the alpha level adopted in our study $(\mathrm{p}=0.05)$.

\section{Conclusion}

The results of our study show that Bovhyaluronidaze azoximer has an anti-inflammatory effect, reduces the severity of edema and prevents the formation of a pocket of chronic infection, so the use of Bovhyaluronidaze azoximer in the form of rectal suppositories as part of the complex treatment of purulent-inflammatory processes in companion animals statistically significantly reduces treatment duration, accelerates the purification of wounds from purulonecrotic contents, accelerates the decline of edema and the reduces the number of wound managements required.

Since hyaluronidase is covalently bound to a highmolecular carrier, Bovhyaluronidaze azoximer is resistant to denaturing agents and has a prolonged action, which makes its use convenient. The ease of use increases the compliance of companion animal owners.

In addition, due to the conjugation of hyaluronidase, it became possible to use it in the acute phase of the inflammatory process, which is very important for purulent wounds and abscesses treatment.

\section{References}

1. Interfax 04.10.2018 Retrieved from: https://www.interfax.ru/russia/631927

2. C. O'Meara, B.L. Boyanton, D. Spurlin, C.F. Carpenter, Infect. Diseas. in Clin. Pract., 24(2), 112-114 (2016)

3. V.D. Palumbo, P. Tralongo, B.Di. Trapani, F. Carini, G. Tomasello, Clin. Terapeut., 170(5), E328-E331 (2019)

4. C. Nhan, A. Bezdjian, S. Saha, S. Prakash, L.H.P. Nguyen, S.J. Daniel, J. of Otolaryng.-Head \& Neck Surgery, 46 (2017)

5. M.E. Ahmed, S.H. Seddiq, R.Q. Basi, G.A. Abdulhasan, A.Q. Al-Awadi, Res. J. of Pharmac. Biolog. and Chem. Sci., 9(2), 1186-1196 (2018)

6. Z. Hadisi, J. Nourmohammadi, S.M. Nassiri, Int. J. of Biolog. Macromolec., 107, 2008-2019 (2018)

7. A. Nazarova, B. Semenov, A. Bokarev, A. Nechaev, Coll. of sci. papers of the Ninth int. Interuniver. Conf. on Clin. Veter. Med., pp. 97-110 (2019)

8. A. Stekolnikov, A. Nazarova, B. Semenov, T. Kuznetsova, Int. bull. of Veter. Med., 4, 158-165 (2019)

9. GOST R 58090-2018 Clinical examination of unproductive animals. General requirements (2018)

10. R. Habriyev, N. Kamayev, T. Danilova, E. Kakhoyan, Biomed. Chem., 62(1), 82-88 (2016)

11. Yu. Alyayev, Ye. Lartsova, L. Spivak, Effect. Pharmacother., 49, Urol. and Nephrol., 5, 4-8 (2015) 